\title{
A NEW SPECIES OF Paratelenomus (HYMENOPTERA: SCELIONIDAE) FROM INDIA
}

\author{
K. Rajmohana ${ }^{1}$ and T.C. Narendran ${ }^{2}$
}

\begin{abstract}
${ }^{1}$ Zoological Survey of India, Western Ghats Field Research Station, Kozhikode, Kerala 673002, India
${ }^{2}$ Systematic Entomology Laboratory, Department of Zoology, University of Calicut, Kerala 673635, India Email: ${ }^{1}$ raj_mohana@hotmail.com; ${ }^{2}$ drtcnarendran@yahoo.com
\end{abstract}

\begin{abstract}
A new species of the subfamily Telenominae Paratelenomus mangrovus is described and illustrated. Its position within the genus and affinities with other species are discussed. A key to distinguish the three Indian species of Paratelenomus is provided.
\end{abstract}

\section{KEYWORDS \\ Hymenoptera, key, new species, Paratelenomus mangrovus sp. nov., Scelionidae}

Telenomines are egg parasitoids of a wide group of agricultural pests belonging to insect orders Lepidoptera, Heteroptera and Homoptera. Not much has been published on the taxonomy and diversity of the subfamily Telenominae of the Indian subcontinent. Our studies indicate that among telenomines, Telenomus Haliday forms the most ubiquitous and the most species-rich genus. Other genera like Psix Kozlov and Le, Paratelenomus Dodd and Mudigere Johnson are only occasionally encountered.

In this paper, we describe a new species of telenomine, Paratelenomus mangrovus sp. nov. along with a key to distinguish the Indian species. Of a total of eight species hitherto known worldwide, only two species, namely $P$. saccharalis (Dodd) and P. striativentris (Risbec) are so far reported from India (Johnson, 1996).

The host data of Paratelenomus is recorded only for one species, viz., $P$. saccharalis, from eggs of Plataspididae Narendran, 2001).

The specimens of the new species were collected by netsweeping on the vegetation on a mangrove area, dominated by species like Avicennia officinalis (Verbenaceae), Excoecaria agallocha (Euphorbiaceae), Acanthus ilicitolius (Acanthaceae) and Derris trifoliata (Fabaceae).

Morphological terminology follows that of Masner (1979, 1980), and Johnson \& Masner (1985). The characters considered and described for species analysis are as per Johnson (1996).

The type specimens are deposited at Zoological Survey of India, Kozhikode (ZSIC).

\section{Paratelenomus mangRoves SP. NOV.}

$$
\text { (Figs. 1-4) }
$$

\section{Material examined}

Holotype: Female, 28.xi.2005, mangrove, Cheruvannur, Kozhikode, Kerala, India, coll. Mohana, ZSI/I/Hy/Sc.-1, glued laterally on card point, entire

Paratype: One female: collection data same as holotype; ZSI/ (Hemiptera: Heteroptera) (Johnson 1996; Rajmohana \&

I/Hy/Sc.-2, glued laterally on card rectangle, entire.

\section{Etymology}

The species name 'mangrovus' refers to the collection site, a mangrove.

\section{Description}

Female: Length $-0.95 \mathrm{~mm}$. Body black; first metasomal tergite, xanthic, noticeably contrasting with rest of body; mesosomal base including metapleuron also with a xanthic tinge; antenna including radicle but excluding terminal three club segments, mandibles and legs pale brown; terminal three club segments brownish-black.

Head: Central keel complete; submedian carina extending almost to midway height of eyes, merging with longitudinal rugulae and raised setal bases extending down from pustulate vertex; frons between submedian carinae smooth; a row of setae present along submedian carinae; orbital carina continuous along inner eye margin past lateral ocellus; traces of one or two parallel rugulae between submedian and orbital carina, more proximal to submedian carina, near base; four ridges radiating fan-like from anterior mandibular articulation, extending between malar sulcus and orbital carinae, ridges ending forked near orbital margin; genal carina doubled, lower one hardly extending to level of lower eye margin and only three-fourth of ridge on top, forming a distinct sulcus in between; two more ridges eventually forming another sulcus between malar sulcus and genal carina; gena almost completely pustulate behind genal carina, less coriaceous; pustules much dense towards mandibular articulation; crenulae arising from occipital carina short; clypeus/labrum ligulate, apex almost pointed; far surpassing closed mandibles; radicle concolorous with scape; antennal clava pentamerous.

Mesosoma: Notauli present, extending from transscutal articulation over half length of mesoscutum, weakly narrowed and shallow apically; mesoscutum with scaly reticulate microsculpture throughout, scutellum with transscutal articulation and crenulae wide laterally, but narrower medially, scutellum not abutting mesoscutum; crenulae along posterior margin almost as wide medially as laterally; disc of scutellum with similar, but finer sculpture as on mesoscutum, setal bases raised; 4 or 5 small crenulae flanking pro and meso-coxal cavities, but not confluent medially; intercoxal space not margined by crenulae; acetabular field large; anteroventral portion of mesepisternum with finely coracious, pustulate and setose acetabular field; three to four episternal fovea extending towards mesopleural pit; mesopleural carina visible as a poorly differentiated ridge, without foveae marking anterior margin; mesopleural scrobe deep, bordered posteriorly by a curved

Manuscript 1631; (C ZOO; Date of publication 21 December 2006 Received 01 September 2006; Finally accepted 01 December 2006; 


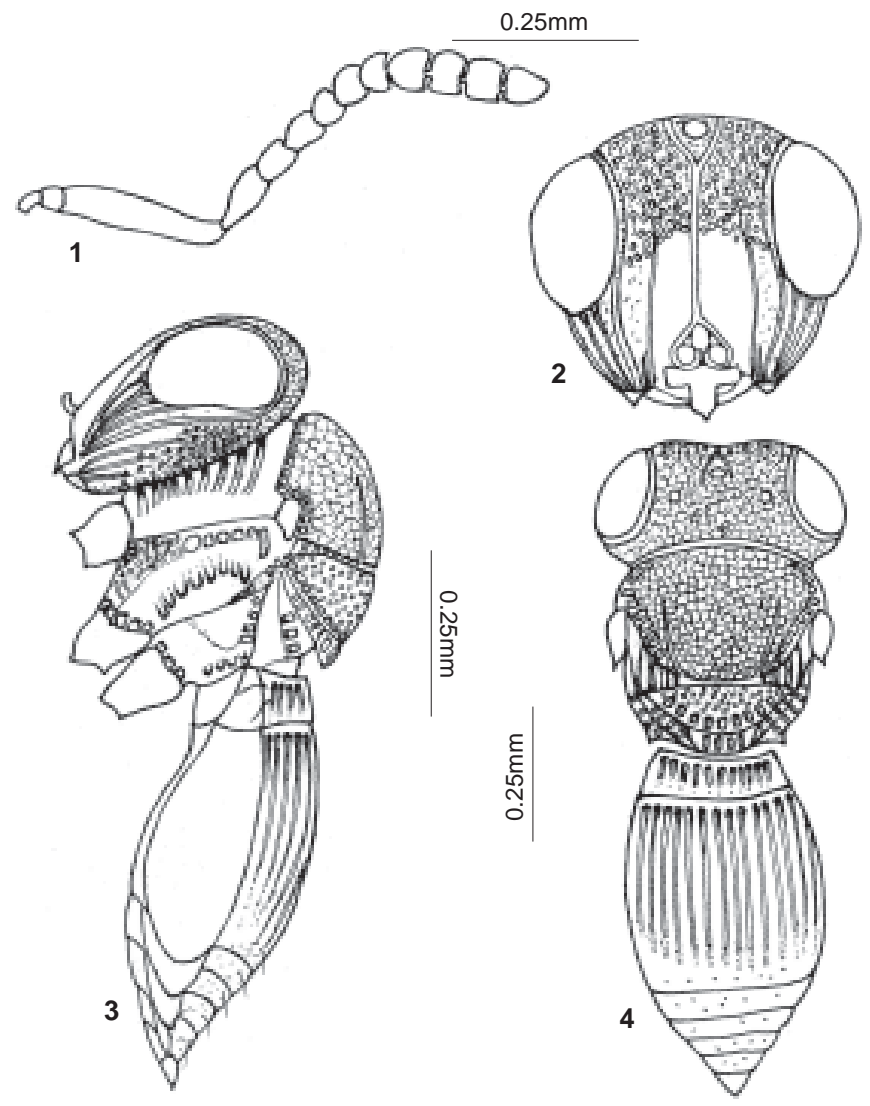

Figures 1-4. Paratelenomus mangrovus sp. nov. (Female) 1 - Antenna; 2 - Head (Front View); 3 - Body (Profile); 4 - Body (Dorsal view)

row of fovea near post epimeron; latter with four or five pits towards base of forewing; metapleural triangle well marked; metapleural carina weakly indicated; meso-metapleural suture not flanked by fovea or crenulae on metapleuron but with a fine coriaceous patch towards hind coxa.

Metasoma: First segment with two lateral setae; apex of second tergite with band of very fine microsculpture.

Male: Unknown.

Biology: Unknown.

\section{Discussion}

This new species runs to couplet 7 of the key to world species of Paratelenomus by Johnson (1996). P. mangrovus sp. nov. has a strong resemblance to $P$. tetartus (Crawford) in particular to much of the frontal, mesoscutal and metasomal characters. The major difference between the two species is in the detailed sculpture of the mesopleuron. The elaborate mesopleural sculpture in this group is of great relevance in distinguishing the species. This is in addition to definite differences in some other characters like nature of notauli, scutellum and post gena.

The following comparison distinguishes the two species easily. In $P$. mangrovus sp. nov.: (i) Crenulae flanking pro and meso-coxal cavities not confluent medially; (ii) Episternal fovea three to four; and (iii) Orbital carina encircling the inner eye margin, past lateral ocellus. In P. tetartus (Crawford): (i) Crenulae flanking pro and meso-coxal cavities confluent medially; (ii) Episternal fovea present as a single large pit; and (iii) Orbital carina not extending to lateral ocellus.

It has to be noted that the length of the submedian carina is to be considered as a variable character as in the case of $P$. saccharalis (Johnson, 1996). In the paratype of P. mangrovus sp. nov., this carina was seen to continue dorsally, finally merging with the vertexal sculpture.

Among the eight species of Paratelenomus, such a ligulate clypeus/labrum, which is medially drawn out into a long point is seen only in two other species namely, P. tetartus and P. ophiusa (Dodd). But $P$. ophiusa is distinct from the rest by its lack of notauli.

\section{REFERENCES}

Johnson, N.F. (1996). Revision of world species of Paratelenomus Dodd (Hymenoptera: Scelionidae). The Canadian Entomologist 128: 273-291. Johnson, N.F. \& L. Masner (1985). Revision of the genus Psix Kozlov \& Le (Hymenoptera: Scelionidae). Systematic Entomology 10: 33-58. Masner, L. (1979). Pleural morphology in scelionid wasps - an aid to higher classification. The Canadian Entomologist 111: 1097-1087.

Masner, L. (1980). Key to genera of Scelionidae of the Holarctic Region, with description of new genera and species. (Hymenoptera: Proctotrupoidea). Memoirs of the Entomological Society of Canada 113: 54 .

Rajmohana, K. \& T.C. Narendran (2001). Parasitoid complex of Coptosoma cribraria (Heteroptera). Insect Environment 6(4): 163.

\section{ACKNOWLedgement}

The first author is grateful to the Director, Zoological Survey Of India, Kolkata and the Officer-in-Charge, ZSI, Kozhikode, for encouragement and facilities provided. Thanks are due to Professor Norman F. Johnson, Ohio State University, Columbus, USA, for critically reviewing the manuscript and providing helpful comments. The grant of a research associateship by the Council of Science and Industrial Research, New Delhi, for a part of this study is also hereby acknowledged.

Key to Paratelenomus Dodd of the Indian Region (based on females)

1. Mesopleural carina absent, scrobe not margined anteriorly by a row of foveae ........................................... 2

1A. Mesopleural carina indicated by a row of foveae arising from near mid coxal articulation, extending dorsad along anterior edge of scrobe towards mesopleural pit Paratelenomus striativentris (Risbec)

2. Clypeus/labrum drawn out medially into a long point ......................... Paratelenomus mangrovus sp. nov.

2A. Clypeus/ labrum much wider than long, terminating apically in two small submedian teeth..... Paratelenomus saccharalis (Dodd) 